\title{
Kinetic Limitations in Cycled Ni-Rich NCM Cathodes and Their Effect on the Phase Transformation Behavior
}

Simon Schweidler, ${ }^{\dagger}$ Lea de Biasi, ${ }^{\dagger}, \$$ Pascal Hartmann, ${ }^{\dagger, \dagger}$ Torsten Brezesinski, ${ }^{\dagger}, *$ and Jürgen Janek $^{\dagger, \#, *}$

${ }^{\dagger}$ Battery and Electrochemistry Laboratory, Institute of Nanotechnology, Karlsruhe Institute of Technology (KIT), Hermann-von-Helmholtz-Platz 1, 76344 Eggenstein-Leopoldshafen, Germany.

${ }^{\S}$ Institute for Applied Materials-Energy Storage Systems, Karlsruhe Institute of Technology (KIT), Hermann-von-Helmholtz-Platz 1, 76344 Eggenstein-Leopoldshafen, Germany.

*BASF SE, Carl-Bosch-Strasse 38, 67056 Ludwigshafen, Germany.

"Institute of Physical Chemistry \& Center for Materials Science, Justus-Liebig-University Giessen, Heinrich-Buff-Ring 17, 35392 Giessen, Germany.

\section{TOC Graphic}

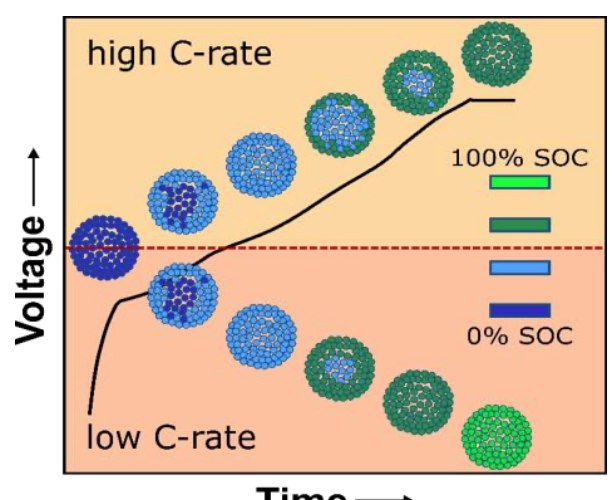




\begin{abstract}
Layered lithium transition-metal oxides of the general formula $\mathrm{Li}_{1+x}\left(\mathrm{Ni}_{1-y-z} \mathrm{Co}_{y} \mathrm{Mn}_{\mathrm{z}}\right)_{1-x} \mathrm{O}_{2}$ (NCM or NMC) represent a promising class of cathode active materials for Li-ion battery applications. However, especially Ni-rich NCMs, enabling high capacity and energy density, tend to undergo more severe degradation during cycling than low and medium Ni materials. In this work, the kinetics of phase transitions in cycle-aged $\mathrm{Li}_{1+x}\left(\mathrm{Ni}_{0.85} \mathrm{Co}_{0.1} \mathrm{Mn}_{0.05}\right)_{1-x} \mathrm{O}_{2}$ (NCM851005) upon electrochemical (de-)lithiation have been studied by operando X-ray diffraction. The focus is set on the onset of kinetic impairment, evident from the coexistence of differently delithiated phases for cell voltages greater than $\sim 4.1 \mathrm{~V}$ after $\geq 150$ cycles, to examine if the behavior observed with NCM851005 is analogous to the H2-H3 transformation in isostructural $\mathrm{LiNiO}_{2}(\mathrm{LNO})$.
\end{abstract}

\title{
Keywords
}

lithium-ion battery, lithium nickel cobalt manganese oxide, high-voltage phase transition, kinetic impairment

\section{Introduction}

For the electrification of cars, the battery must meet highest demands in terms of energy density and cycle life. In that respect, the active electrode materials are playing a crucial role. The current materials of choice at the positive electrode side are layered lithium-transition metal oxides of the types $\mathrm{Li}_{1+x}\left(\mathrm{Ni}_{1-y-z} \mathrm{Co}_{y} \mathrm{Mn}_{\mathrm{z}}\right)_{1-x} \mathrm{O}_{2}(\mathrm{NCM})$ and $\mathrm{Li}_{1+x}\left(\mathrm{Ni}_{1-y-z} \mathrm{Co}_{y} \mathrm{Al}_{z}\right)_{1-x} \mathrm{O}_{2}(\mathrm{NCA}) .{ }^{1-3}$ To achieve sufficiently high specific capacities at a given maximum voltage, the Ni content of NCMs is continuously increased. ${ }^{1,2,4}$ However, this implies some difficulties and disadvantages. Ni-rich NCMs suffer from accelerated capacity fading and lower thermal stability compared to low Ni materials. ${ }^{4}$ This is partially because of structural and morphological changes (volume expansion/contraction, cation mixing, cracking, etc.) and irreversible phase transformations (spinel or rock salt-type formation), causing degradation of the electrode and strongly affecting the performance, capacity retention, and overall lifetime of the cell. ${ }^{4-14}$ For example, de Biasi et al., ${ }^{9}$ Kondrakov et al., ${ }^{13}$ Noh et al.,${ }^{15}$ and Ryu et al. ${ }^{16}$ have shown that increasing the Ni content has a significant effect on the volume changes of the NCM crystallites and is related to fracturing of the secondary particles. 
The degradation behavior of $\mathrm{Li}_{1+x}\left(\mathrm{Ni}_{0.85} \mathrm{Co}_{0.1} \mathrm{Mn}_{0.05}\right)_{1-x} \mathrm{O}_{2}(\mathrm{NCM} 851005)$ cathode material has been studied recently. ${ }^{17}$ Here, we build on the results of our previous study, in which NCM851005/graphite pouch cells were cycled at a $1 \mathrm{C}$ rate and $45{ }^{\circ} \mathrm{C}$ between 2.8 and $4.2 \mathrm{~V}$ for several hundreds of cycles and studied by operando X-ray diffraction (XRD). After $\geq 150$ cycles, XRD revealed a distinct broadening of the Bragg reflections for voltages greater than $\sim 4.1 \mathrm{~V}$. The occurrence of this broadening is assumed to be related to a coexistence of two differently delithiated phases (considered as one less and one more delithiated). In general, the coexistence of two hexagonal phases at high states of charge (SOC), namely $\mathrm{H} 2$ and $\mathrm{H} 3$, is well known from isostructural $\mathrm{LiNiO}_{2}$ (LNO) cathode material, the endmember of the NCM family. ${ }^{18-21}$ This two-phase coexistence is also assumed to be present in Ni-rich NCMs. ${ }^{15-17}$ Interestingly, the broadening of reflections becomes stronger with increasing cycle life, probably as a consequence of the progressive degradation processes. Structural refinement also showed that at the end of charge, the fraction of the more delithiated phase decreases, while that of the less delithiated phase increases until only the latter remains after 750 cycles. The results indicate that local environments with different kinetics may be responsible for the heterogeneous Li-extraction capability, leading to separation into a 'more active' phase and a 'less active' phase.

Based on the results from our previous study, new findings regarding crystallographic changes of the differently delithiated phases, taking place during an equilibration period, are being analyzed and discussed below. Furthermore, additional measurements were performed on the cycle-aged NCM851005/graphite cells. For this purpose, after 250 cycles, the pouch cells were cycled at different C-rates while XRD was conducted to determine kinetic limitations and to define the range of (de-)lithiation where a possible impairment may occur. In addition, we focus on a deeper investigation of the phase transformation behavior of NCM851005 and particularly the possible analogues to the $\mathrm{H} 2-\mathrm{H} 3$ transition in LNO.

\section{Experimental Section}

\section{Materials and Electrochemical Testing}

NCM851005 was received from BASF SE (Germany). The electrodes had a loading of $~ 2$ $\mathrm{mAh} / \mathrm{cm}^{2}$ and consisted of $94 \mathrm{wt} \%$ active material, $3 \mathrm{wt} \%$ PVDF binder, $2 \mathrm{wt} \%$ SFG6L conductive carbon and 1 wt\% Super C65 carbon black (Timcal). The electrodes were calendared to a density of $\sim 3.2 \mathrm{~g} / \mathrm{cm}^{3}$ and electrochemically tested in single-layer pouch cells. The cells were assembled inside a dry room with dew point below $-60{ }^{\circ} \mathrm{C}$ and contained an 
NCM851005 cathode $\left(50.50 \mathrm{~mm}^{2}\right)$, a graphite anode $\left(51.51 \mathrm{~mm}^{2}\right)$, a Celgard 2500 polypropylene separator $\left(53.53 \mathrm{~mm}^{2}\right)$, and $500 \mu \mathrm{L} \mathrm{LP472}$ electrolyte $(1 \mathrm{M} \mathrm{LiPF} 6$ in 3:7 by weight of ethylene carbonate and diethyl carbonate plus 2 wt\% vinylene carbonate). Experimental details of the assembling of pouch cells and the cycling procedure can be found elsewhere. ${ }^{17}$ After both the formation cycles at different C-rates and the long-term cycling at a $1 \mathrm{C}$ rate (with $1 \mathrm{C}=192 \mathrm{~mA} / \mathrm{g}_{\mathrm{NCM}} 851005$ ) and $45^{\circ} \mathrm{C}$ in the voltage range between 2.8 and $4.2 \mathrm{~V}$, the cells were transferred directly to the diffractometer.

\section{Characterization}

Operando XRD data were collected on a custom high-intensity laboratory diffractometer with a molybdenum micro-focus rotating anode and a Pilatus 300K-W area detector. Details of the setup used are reported elsewhere. ${ }^{22}$ Patterns were collected between 7.1 and $44.3^{\circ} 2 \theta$ with an exposure time of $90 \mathrm{~s}$. The intensity of two patterns was added up and integrated to generate spike-noise-free $1 \mathrm{D}$ patterns of total time resolution 180 s. Annealed $\mathrm{CeO}_{2}$ served as a calibration sample to determine the instrumental resolution using the Thompson-Cox-Hastings pseudo Voigt function. ${ }^{23}$ The Rietveld analysis comprised refinement of the lattice parameters $a$ and $c$ and the atomic coordinate $z$ of the oxygen position of NCM851005 and of the lattice parameter $c$ of graphite. The graphite lattice parameter $a$ was fixed to values from our earlier results because of overlapping reflections with the NCM851005/Al/Cu reflections. ${ }^{24}$ Background refinement was done using a linear interpolation function comprising 36 parameters.

\section{Results and Discussion}

From literature, it is known that a monoclinic distortion of the layered lattice takes place in the NCM851005 during cycling (based on the course of the charge trace between $\sim 3.8$ and $3.95 \mathrm{~V}$ and the discharge trace between $\sim 3.7$ and $3.5 \mathrm{~V}$ ). However, because of the limited angular resolution of the XRD setup used and the overlap of reflections with high-intensity $\mathrm{Al} / \mathrm{Cu}$ reflections from the pouch foil and the current collectors (Figure S1), a clear distinction between the rhombohedral $(R \overline{3} m)$ and monoclinic $(C 2 / m)$ phases is not possible. Hence, the layered $\alpha-\mathrm{NaFeO}_{2}$-type structure $(R \overline{3} m)$ was used in the Rietveld analysis, and the changes from the rhombohedral to the monoclinic phase were neglected. ${ }^{13,25-27}$ The nickel, cobalt, and manganese ions are assumed to be randomly distributed in the Wyckoff $3 b$ positions, while the lithium ions occupy the Wyckoff 3 a positions in the interslab space (see schematic of the crystal 
structure in the inset of Figure 1a). Because the $R \overline{3} m$ symmetry allows for some variation of the $z$-coordinate of oxygen, its value was refined in a limited range of $0.22 \leq z \leq 0.26$. The $\mathrm{Al}$ (pouch foil and cathode current collector) and $\mathrm{Cu}$ (anode current collector) phases and the NCM and graphite phases were refined via Pawley and Rietveld refinement, respectively. In addition, the operando XRD analysis focuses on the 003 reflection of NCM851005, since it has the highest intensity, shows no superposition with other reflections, and is a clear indicator for the SOC. ${ }^{13}$

During the XRD measurement, the cell was cycled at a rate of $\mathrm{C} / 5$ or $\mathrm{C} / 10$ and $25{ }^{\circ} \mathrm{C}$ in the voltage range between 2.8 and $4.2 \mathrm{~V}$. Subsequently, the structural changes were analyzed via Rietveld refinement (Figure S1). Because of partial overlapping of reflections, no information regarding the $\mathrm{Li} /$ transition metal mixing was obtained (i.e., the occupancy was not refined). Figure 1a-d shows the voltage profile of a cycle-aged NCM851005/graphite cell during charging at a $\mathrm{C} / 10$ rate and the detected changes in lattice parameter $c$, unit-cell volume, and phase fraction.

a)

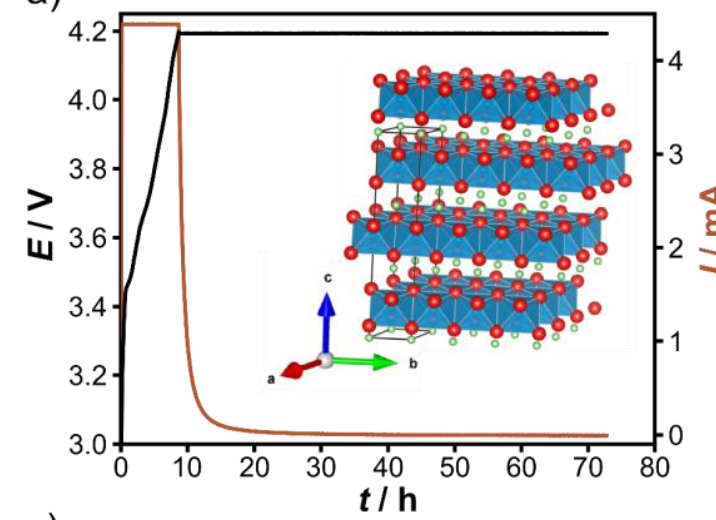

c)

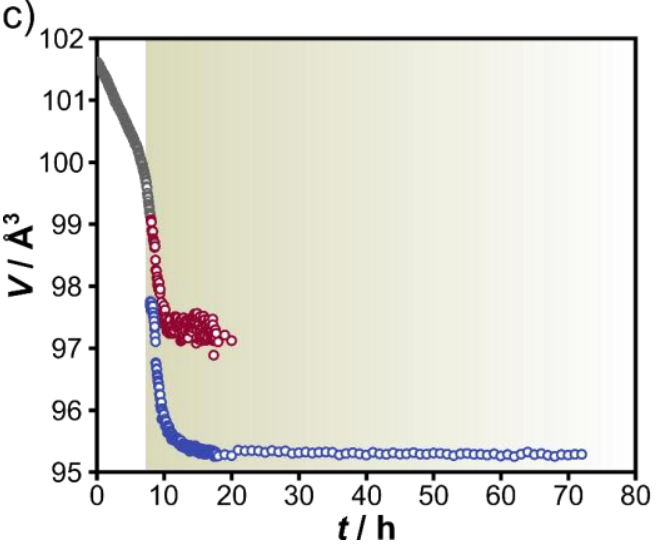

b)

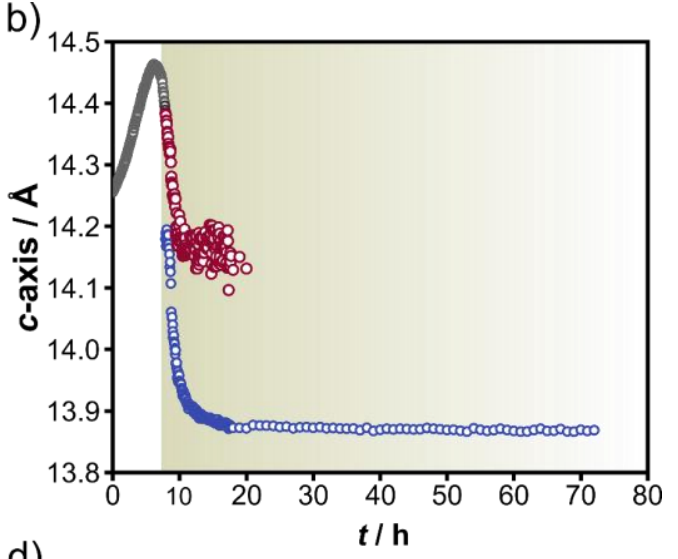

d)

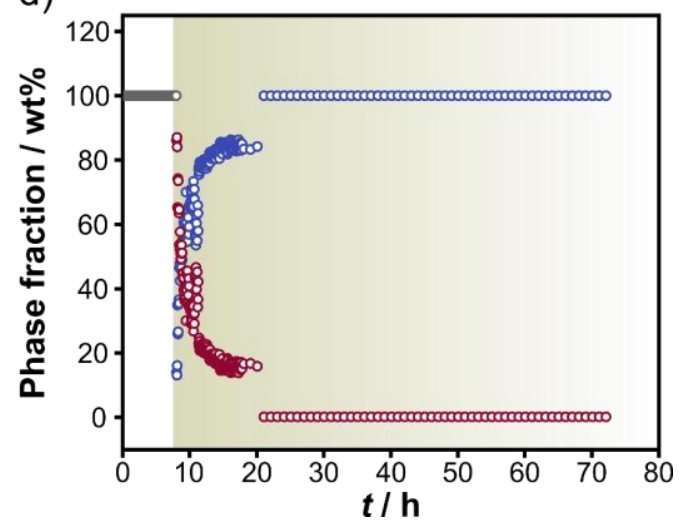

Figure 1. Structural refinement results for the cycle-aged NCM851005. (a) Evolution of voltage and current of the NCM851005/graphite pouch cell during charging at C/10 and $\sim 60 \mathrm{~h} \mathrm{CV}$ period at $4.2 \mathrm{~V}$. The NCM crystal structure, with the oxygen in red, lithium in green, and transition metals in dark blue, is schematically shown in the inset. (b-d) Corresponding changes 
in lattice parameter $c$, unit-cell volume, and phase fraction. The single-phase region is in gray, the less and more active NCM phases in the two-phase region are shown in red and blue, respectively. The two-phase region is highlighted for clarity. Note that the abrupt changes in $c$ axis, unit-cell volume, and phase fraction values after $\sim 8$ and $20 \mathrm{~h}$ of charging are because of the constraints in the refinement procedure.

During charging and the concomitant delithiation process of the NCM851005, there is a constant decrease in $a$-axis from initially $2.869(3)$ to $2.816(5) \AA$ (Figure S2). The lattice parameter $c$, at first, shows an increase from 14.255(2) to 14.464(2) $\AA$ and then a rapid decrease, which is typically denoted as a collapse. The evolution of lattice parameters is characteristic of NCMs and has been well discussed in literature. ${ }^{9,10,13,28,29}$ For cell voltages greater than $4.13 \mathrm{~V}$, a two-phase region is detected, consisting of a less and a more active NCM phase (Figure S3). Note that in both cases the $\alpha-\mathrm{NaFeO}_{2}(R \overline{3} m)$ structure model was used in the Rietveld analysis. The different phases were identified based on their distinctive 003 reflection, which is directly correlated to the lattice parameter $c$. In turn, the lattice parameter $c$ provides information about the layer distance and can be correlated to the amount of $\mathrm{Li}$ in the structure., ${ }^{9,13,30,31}$ After reaching the upper cutoff voltage, a constant voltage (CV) step was applied for $\sim 60 \mathrm{~h}$. During this CV step, an 'equilibration', i.e., a decrease in broadening of the 003 reflection (because of growth of the reflection of the more active phase on cost of that of the less active phase), is detected. Hence, the fraction of the less active NCM phase continuously decreases, while that of the more active phase increases (Figure 1). Furthermore, in the case of the less active NCM phase, abrupt changes in the $c$-axis and unit-cell volume values are observed during Rietveld refinement until its exclusion when reaching a fraction of $<10 \mathrm{wt} \%$. Note that the reflections become increasingly broader and the refinement error becomes large, leading to increased scattering of the refined parameters. The increasing peak width is indicative of increasing heterogeneity, where individual reflections overlap in a broader peak (Figure S4). This probably suggests that there are several NCM fractions of different SOC present in the cycled NCM851005 electrode. The results clearly show that, in contrast to LNO where the H2-H3 transformation is taking place in a typical two-phase reaction (peak splitting), ${ }^{18,19}$ the behavior of NCM851005 significantly deviates from this simple model.

To identify whether the observed phase separation is caused by (heterogeneous) kinetic limitations along individual NCM domains (giving the impression of a phase transformation similar to LNO) or whether it is due to a classical phase transformation that is kinetically 
hindered, a C-rate-dependent analysis was performed. For a two-phase transformation, the transition should take place at the same SOC for various C-rates when taking the overvoltage because of internal resistance into account. Figure 2a depicts the evolution of reflection positions and intensities for the NCM851005/graphite cell in a contour plot with the corresponding voltage profile. Furthermore, Figure $\mathbf{2 b - d}$ shows the changes in $c$-axis during cycling at rates of $\mathrm{C} / 5$ and $\mathrm{C} / 10$ with a $1 \mathrm{~h} \mathrm{CV}$ step at $4.2 \mathrm{~V}$ and of $\mathrm{C} / 10$ with a $>30 \mathrm{~h}$ opencircuit voltage (OCV) step at the end of charge. Hereafter, the different cycles are referred to as $\mathrm{C} / 5-\mathrm{CV}, \mathrm{C} / 10-\mathrm{CV}$, and $\mathrm{C} / 10-\mathrm{OCV}$. The results from Rietveld analysis are listed in Table $\mathbf{1}$.

a)
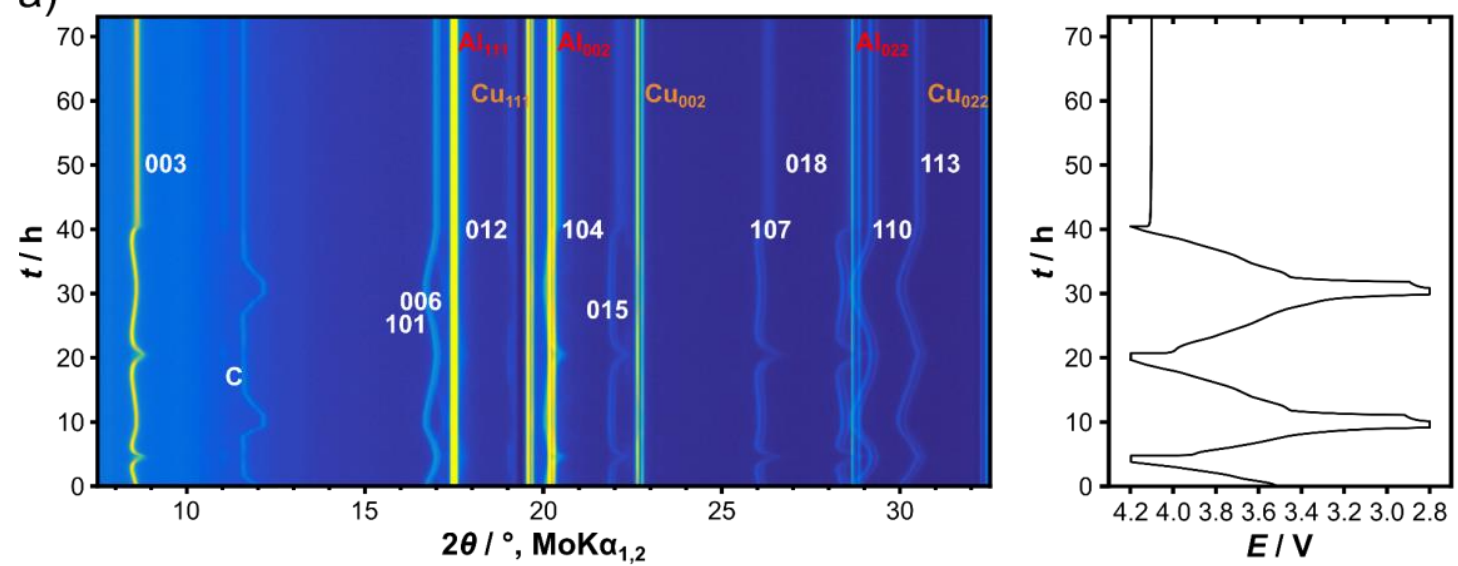

b)

C)
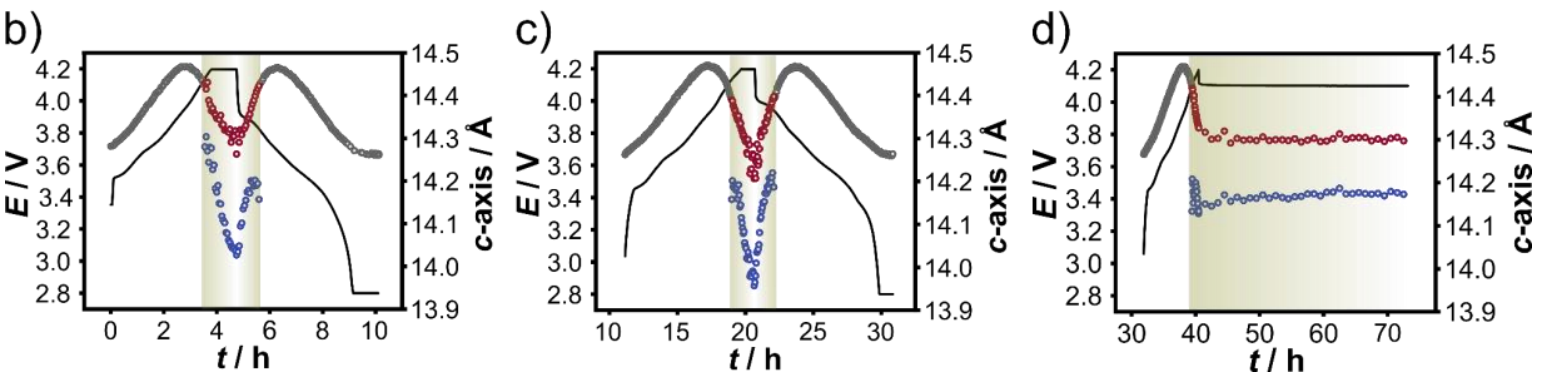

Figure 2. (a) Contour plot of operando XRD patterns and the corresponding voltage profile for the cycle-aged NCM851005/graphite pouch cell. Changes in lattice parameter $c$ of the NCM851005 (b) at C/5 and (c) C/10 with $1 \mathrm{~h} \mathrm{CV}$ steps at 4.2 and $2.8 \mathrm{~V}$ and (d) at C/10 for charge with $\sim 30 \mathrm{~h} \mathrm{OCV}$ period at $4.2 \mathrm{~V}$. Note that there was also a $1 \mathrm{~h} \mathrm{OCV}$ period at the end of discharge. The single-phase region is in gray, the less and more active NCM phases in the two-phase region are shown in red and blue, respectively. The two-phase region is highlighted for clarity. 
Table 1. Structural refinement results for the cycle-aged NCM851005 from the operando XRD study in Figure 2.

\begin{tabular}{|c|c|c|c|c|c|c|}
\hline Cycle & & $\begin{array}{l}\text { Beginning } \\
\text { of CC } \\
\text { charging }\end{array}$ & $\begin{array}{l}\text { Collapse } \\
\text { region }\end{array}$ & $\begin{array}{l}\text { Beginning of two-phase } \\
\text { region }\end{array}$ & $\begin{array}{l}\text { End of } \mathrm{CC} \\
\text { charging }\end{array}$ & $\begin{array}{l}\text { End of CV } \\
\text { or OCV }\end{array}$ \\
\hline \multirow{5}{*}{$\begin{array}{l}\mathrm{C} / 5- \\
\mathrm{CV}\end{array}$} & $E / \mathrm{V}$ & 3.35 & 3.96 & 4.15 & 4.2 & 4.2 \\
\hline & $q_{\mathrm{ch}} / \mathrm{mAh} / \mathrm{g}$ & - & 110.1 & 137.1 & 142.9 & 162.4 \\
\hline & $a$-axis $/ \AA$ & $2.8667(1)$ & $2.8288(2)$ & $\begin{array}{l}\text { Less active NCM: } 2.8235(5) \\
\text { More active NCM: } 2.816(6)\end{array}$ & $\begin{array}{l}2.8225(4) \\
2.816(4)\end{array}$ & $\begin{array}{l}2.822(1) \\
2.8172(4)\end{array}$ \\
\hline & $c$-axis $/ \AA$ & $14.282(1)$ & $14.469(2)$ & $\begin{array}{l}\text { Less active NCM: } 14.430(3) \\
\text { More active NCM: } 14.28(3)\end{array}$ & $\begin{array}{l}14.378(2) \\
14.22(2)\end{array}$ & $\begin{array}{l}14.263(7) \\
14.026(4)\end{array}$ \\
\hline & $V / \AA^{3}$ & $101.64(1)$ & $100.28(2)$ & $\begin{array}{l}\text { Less active NCM: } 99.63(4) \\
\text { More active NCM: } 98.10(19)\end{array}$ & $\begin{array}{l}99.20(3) \\
97.73(1)\end{array}$ & $\begin{array}{l}98.38(9) \\
96.41(5)\end{array}$ \\
\hline \multirow{5}{*}{$\begin{array}{l}\mathrm{C} / 10- \\
\mathrm{CV}\end{array}$} & $E / \mathrm{V}$ & 3.04 & 3.92 & 4.13 & 4.2 & 4.2 \\
\hline & $q_{\mathrm{ch}} / \mathrm{mAh} / \mathrm{g}$ & - & 117.9 & 152.9 & 166.5 & 177.2 \\
\hline & $a$-axis $/ \AA$ & $2.8701(2)$ & $2.8291(2)$ & $\begin{array}{l}\text { Less active NCM: } 2.8224(3) \\
\text { More active NCM: } 2.822(3)\end{array}$ & $\begin{array}{l}2.8216(7) \\
2.8199(8)\end{array}$ & $\begin{array}{l}2.820(1) \\
2.8191(5)\end{array}$ \\
\hline & $c$-axis $/ \AA$ & $14.262(1)$ & $14.470(1)$ & $\begin{array}{l}\text { Less active NCM: } 14.390(2) \\
\text { More active NCM: } 14.15(2)\end{array}$ & $\begin{array}{l}14.321(4) \\
14.116(5)\end{array}$ & $\begin{array}{l}14.22(1) \\
13.965(4)\end{array}$ \\
\hline & $V / \AA^{3}$ & $101.75(1)$ & $100.31(2)$ & $\begin{array}{l}\text { Less active NCM: 99.27(2) } \\
\text { More active NCM: 97.6(2) }\end{array}$ & $\begin{array}{l}98.74(5) \\
97.21(6)\end{array}$ & $\begin{array}{l}97.9(1) \\
96.12(4)\end{array}$ \\
\hline \multirow{5}{*}{$\begin{array}{l}\mathrm{C} / 10- \\
\mathrm{OCV}\end{array}$} & $E / \mathrm{V}$ & 3.06 & 3.91 & 4.13 & 4.2 & 4.2 \\
\hline & $q_{\mathrm{ch}} / \mathrm{mAh} / \mathrm{g}$ & - & 117.4 & 152.4 & 167.0 & 169.3 \\
\hline & $a$-axis $/ \AA$ & $2.8704(1)$ & $2.8295(2)$ & $\begin{array}{l}\text { Less active NCM: } 2.8227(3) \\
\text { More active NCM: } 2.822(3)\end{array}$ & $\begin{array}{l}2.8217(7) \\
2.8195(7)\end{array}$ & $\begin{array}{l}2.8215(7) \\
2.8206(7)\end{array}$ \\
\hline & $c$-axis $/ \AA$ & $14.266(1)$ & $14.469(2)$ & $\begin{array}{l}\text { Less active NCM: } 14.397(1) \\
\text { More active NCM: } 14.18(2)\end{array}$ & $\begin{array}{l}14.331(5) \\
14.128(6)\end{array}$ & $\begin{array}{l}14.297(4) \\
14.173(5)\end{array}$ \\
\hline & $V / \AA^{3}$ & $101.79(1)$ & $100.33(1)$ & $\begin{array}{l}\text { Less active NCM: } 99.35(3) \\
\text { More active NCM: } 97.7(3)\end{array}$ & $\begin{array}{l}98.83(6) \\
97.26(7)\end{array}$ & $\begin{array}{l}98.57(8) \\
97.65(6)\end{array}$ \\
\hline
\end{tabular}

Again, the typical $c$-axis evolution is detected. ${ }^{9,10,13,22,29}$ In the following, the maximum of the $c$-axis length, which immediately indicates the starting point of layer shrinkage, is referred to as 'collapse region'. At the beginning of each cycle, the lattice parameters $a$ and $c$ are almost identical. The slight differences for the $\mathrm{C} / 5-\mathrm{CV}$ cycle are probably because of the higher initial cell voltage $(3.35 \mathrm{~V})$, suggesting a lower Li concentration at the beginning of charge. In all three cycles, the typical changes in reflection positions of Ni-rich NCM are observed (Figure 2a).

To better understand possible kinetic limitations, the different cycles are compared during charging to the upper cutoff voltage of $4.2 \mathrm{~V}$. First, there is a constant increase in lattice 
parameter $c$ up to a maximum of $14.469(2) \AA$ with $q_{\text {ch }}=110.1 \mathrm{mAh} / \mathrm{g}_{\mathrm{NCM} 851005}, 14.470(1) \AA$ with $q_{\mathrm{ch}}=117.9 \mathrm{mAh} / \mathrm{g}_{\mathrm{NCM} 851005}$, and $14.469(2) \AA$ with $q_{\mathrm{ch}}=117.4 \mathrm{mAh} / \mathrm{g}_{\mathrm{NCM} 851005}$ for the C/5$\mathrm{CV}, \mathrm{C} / 10-\mathrm{CV}$, and $\mathrm{C} / 10-\mathrm{OCV}$ cycles, respectively. As expected, until reaching the collapse region, the $\mathrm{C} / 5-\mathrm{CV}, \mathrm{C} / 10-\mathrm{CV}$, and $\mathrm{C} / 10-\mathrm{OCV}$ cycles show very similar changes in lattice parameters, and only the cell voltage and specific capacity deviate slightly in the case of the $\mathrm{C} / 5$ cycle compared to the $\mathrm{C} / 10$ cycles (Table 1). The differences in specific capacity can probably be explained by the differences in the initial lattice parameters. In addition, an overvoltage of $\sim 100 \mathrm{mV}$ is observed at the beginning of the charging process (arrows in Figure 3). After the collapse region, the $c$-axis continuously decreases for all three cycles.

a)

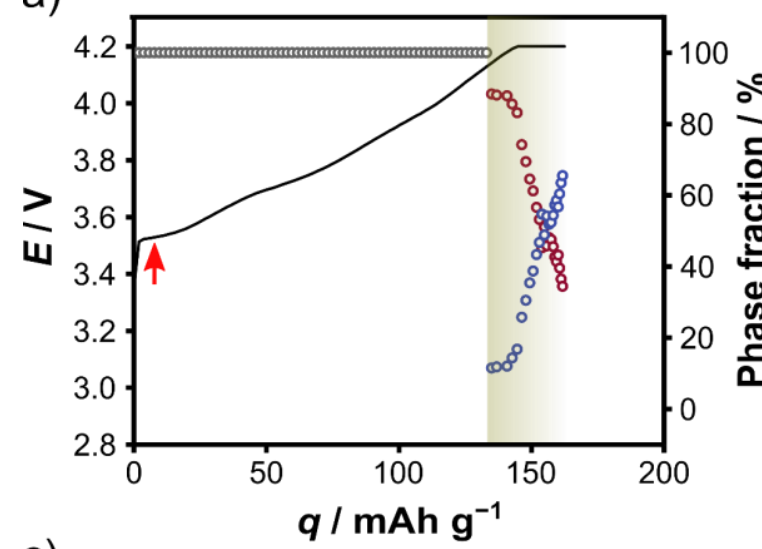

c)

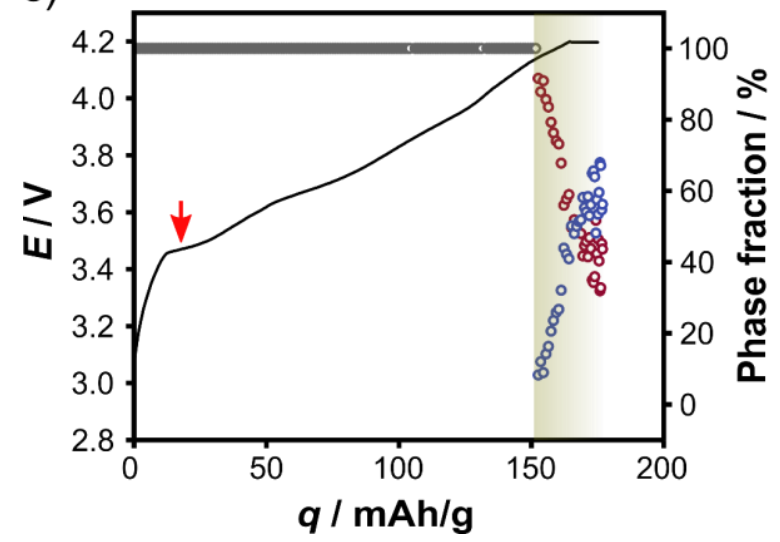

b)

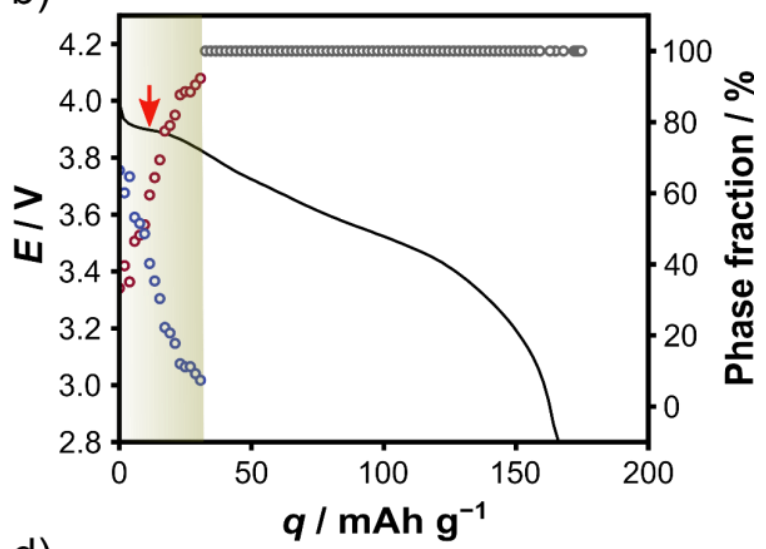

d)

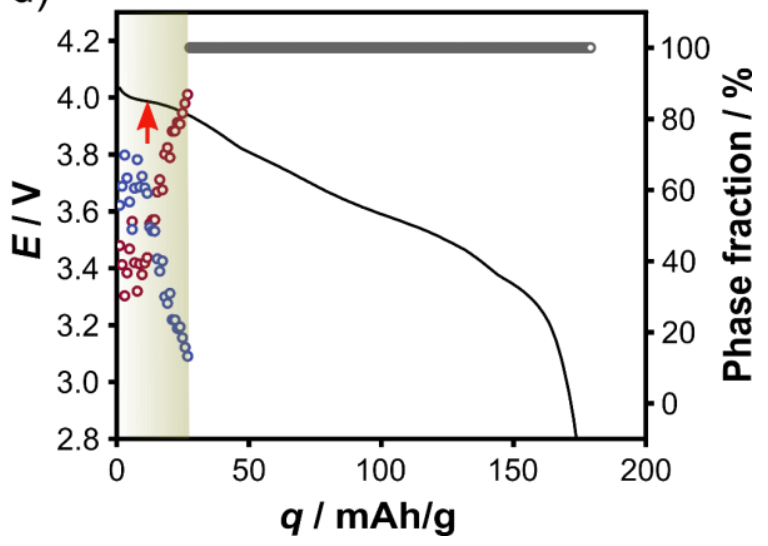

Figure 3. Phase fraction versus specific capacity for (a, b) the $\mathrm{C} / 5-\mathrm{CV}$ and (c, d) C/10-CV cycles. The red arrows indicate the shift in charge/discharge curves because of overvoltage. The single-phase region is in gray, the less and more active NCM phases in the two-phase region are shown in red and blue, respectively. The two-phase region is highlighted for clarity.

In all three cycles, a noticeable broadening of the 003 reflection, i.e., the coexistence of the less and the more active NCM phase, is detected. Furthermore, a slight difference in lattice parameters between the two C-rates can be observed. The C/10-CV and C/10-OCV cycles show 
significant peak broadening and detection of the two phases with reaching a voltage of $4.13 \mathrm{~V}$ and $q_{\mathrm{ch}} \approx 153 \mathrm{mAh} / \mathrm{g}_{\mathrm{NCM} 851005}$ (Table 1). The lattice parameters of the less and the more active phase are comparable for both $\mathrm{C} / 10$ cycles. In the case of the $\mathrm{C} / 5-\mathrm{CV}$ cycle, peak broadening is detected at an almost identical voltage $(4.15 \mathrm{~V})$. While the lattice parameters differ only slightly from the $\mathrm{C} / 10$ cycles, there is a more pronounced difference in the capacity. The same holds for the evolution of lattice parameters and capacity during the CV or OCV step. For the $\mathrm{C} / 5-\mathrm{CV}$ cycle, specific charge capacities of $142.9 \mathrm{mAh} / \mathrm{g}_{\mathrm{NCM} 851005}$ (86 wt\% less active phase and $14 \mathrm{wt} \%$ more active phase) and $162.4 \mathrm{mAh} / \mathrm{g}_{\mathrm{NCM}} 851005$ (34 wt $\%$ less active phase and 66 $\mathrm{wt} \%$ more active phase) are achieved at the end of the constant current (CC) charging and the $\mathrm{CV}$ step, respectively. In the $\mathrm{C} / 10-\mathrm{CV}$ cycle, on the other hand, specific charge capacities of $166.5 \mathrm{mAh} / \mathrm{g}_{\mathrm{NCM} 851005}(52 \mathrm{wt} \%$ less active phase and $48 \mathrm{wt} \%$ more active phase) and 177.2 $\mathrm{mAh} / \mathrm{g}_{\mathrm{NCM} 851005}(32 \mathrm{wt} \%$ less active phase and $68 \mathrm{wt} \%$ more active phase) are achieved (Figure 3).

The degree of delithiation (or SOC) was estimated by comparing the refined lattice parameters of cycle-aged NCM851005 with that of 'pristine' material cycled in a half-cell under identical conditions (Figure S5). The results indicate that the lithium content $x(\mathrm{Li})$ is $\sim 0.46$ for both the $\mathrm{C} / 5-\mathrm{CV}$ and $\mathrm{C} / 10-\mathrm{CV}$ cycles when reaching the collapse region. As expected, there are some differences in $x(\mathrm{Li})$ upon further charging. For example, it is found to be $\sim 0.25(\mathrm{C} / 5-\mathrm{CV})$ and $0.23(\mathrm{C} / 10-\mathrm{CV})$ for the less active phase and $\sim 0.20(\mathrm{C} / 5-\mathrm{CV})$ and $0.17(\mathrm{C} / 10-\mathrm{CV})$ for the more active phase at the end of the CV step.

The C/10-OCV cycle showed constant lattice parameters for the less active phase during the OCV step. In the case of the more active NCM phase, the lattice parameter $c$ increased slightly initially before remaining constant during the further course of the OCV period (Figure S6). Hence, it appears that, similar to the long CV step in Figure 1, there is also a kind of equilibration under OCV conditions. However, here the more active phase equilibrates itself. Overall, this would mean that even the presumed homogeneous active phase exhibits some heterogeneity.

\section{Conclusion}

Taken together, there are no significant differences between the individual cycles during charging until the two-phase region is reached. Because the lattice parameters and the cycling data are comparable, a kinetic limitation, which would have been detected by the different $\mathrm{C}$ rates, can be largely ruled out (no obvious peak broadening). Only from the occurrence of the 
two active phases, a clear distinction between the different $\mathrm{C}$-rates can be made (because of the more strongly different lattice parameters). This means that a kinetic impairment only occurs in the highly delithiated state, which is obviously because of increasing heterogeneity of the NCM851005. Nevertheless, the occurrence of the two-phase region is at almost the same voltage of $4.15(\mathrm{C} / 5-\mathrm{CV})$ and $4.13 \mathrm{~V}(\mathrm{C} / 10-\mathrm{CV}$ and $\mathrm{C} / 10-\mathrm{OCV})$, suggesting that it is a classical biphasic transition (analogous to LNO). Because the lattice parameters differ only slightly, i.e., by far not as strong as in LNO, the region can only be detected as a broadened reflection in the XRD patterns. However, the fact that we notice a constant change in both NCM phase fractions with a constant decrease in lattice parameter $c$ at the same time contradicts the classical twophase transition concept. Note that in an ideal two-phase transition, the proportion of one phase increases at the expense of the other phase, while the lattice parameters for both remain the same throughout that time. ${ }^{18,32}$ Furthermore, the results of our previous study demonstrate that the peak broadening strongly increases with increasing cycle number, indicating increasing kinetic limitations (e.g., by a growing rock-salt-type transition-metal oxide layer or blocking of lithium channels because of transition-metal migration). ${ }^{17}$ In addition, the results of the present study show that the reaction continues during the CV step, which is a clear indication of a kinetic limitation for both C-rates. We therefore assume that up to $\sim 4.1 \mathrm{~V}$, delithiation of the cathode can take place uniformly and homogeneously without significant kinetic impairment. During the further course, delithiation becomes more heterogeneous and kinetically hindered, as differently active phases (at least two) are detected, which gradually transform into the more delithiated NCM phase (more active phase). The presence of an $\mathrm{H} 2-\mathrm{H} 3$ transition analogous to LNO is likely, however, the crystal structures of the two phases are too similar in the case of the NCM851005. With progressive cycle aging, the kinetic limitation, arising from the material degradation, increasingly superimposes the two-phase transformation, eventually giving it the appearance of a heterogeneous solid-solution process. Because of the limits in angular resolution of the XRD analysis, other advanced techniques are needed for a more thorough characterization.

\section{Associated Content}

Supporting Information

Contour plot of operando XRD data and the corresponding Rietveld analysis of the initial pattern; Rietveld results for the lattice parameter $a$ during equilibration; examples of single-, two-, and multi-phase detection; estimation of $x(\mathrm{Li})$ by comparing refined lattice parameters. 


\section{Author Information}

Corresponding Authors

*E-mail: torsten.brezesinski@kit.edu; phone: +49 72160828827.

*E-mail: juergen.janek@kit.edu; phone: +49 6419934500.

ORCID

Simon Schweidler: 0000-0003-4675-1072

Lea de Biasi: 0000-0001-8546-0388

Torsten Brezesinski: 0000-0002-4336-263X

Jürgen Janek: 0000-0002-9221-4756

Notes

The authors declare no competing financial interest.

\section{Acknowledgements}

This study is part of the projects being funded within the BASF International Network for Batteries and Electrochemistry. The authors thank Dr. Holger Geßwein and Dr. Reiner Mönig for providing access to the XRD.

\section{References}

(1) Schipper, F.; Erickson, E. M.; Erk, C.; Shin, J.-Y.; Chesneau, F. F.; Aurbach, D. Review-Recent Advances and Remaining Challenges for Lithium Ion Battery Cathodes. J. Electrochem. Soc. 2017, 164, A6220-A6228.

(2) Nitta, N.; Wu, F.; Lee, J. T.; Yushin, G. Li-Ion Battery Materials: Present and Future. Mater. Today 2015, 18, 252-264.

(3) Erickson, E. M.; Ghanty, C.; Aurbach, D. New Horizons for Conventional Lithium Ion Battery Technology. J. Phys. Chem. Lett. 2014, 5, 3313-3324.

(4) Bak, S. M.; Hu, E.; Zhou, Y.; Yu, X.; Senanayake, S. D.; Cho, S. J.; Kim, K. B.; Chung, K. Y.; Yang, X. Q.; Nam, K. W. Structural Changes and Thermal Stability of Charged 
$\mathrm{LiNi}_{x} \mathrm{Mn}_{y} \mathrm{Co}_{z} \mathrm{O}_{2}$ Cathode Materials Studied by Combined In Situ Time-Resolved XRD and Mass Spectroscopy. ACS Appl. Mater. Interfaces 2014, 6, 22594-22601.

(5) Vetter, J.; Novák, P.; Wagner, M. R.; Veit, C.; Möller, K. C.; Besenhard, J. O.; Winter, M.; Wohlfahrt-Mehrens, M.; Vogler, C.; Hammouche, A. Ageing Mechanisms in Lithium-Ion Batteries. J. Power Sources 2005, 147, 269-281.

(6) Sun, H. H.; Manthiram, A. Impact of Microcrack Generation and Surface Degradation on a Nickel-Rich Layered $\mathrm{Li}\left[\mathrm{Ni}_{0.9} \mathrm{Co}_{0.05} \mathrm{Mn}_{0.05}\right] \mathrm{O}_{2}$ Cathode for Lithium-Ion Batteries. Chem. Mater. 2017, 29, 8486-8493.

(7) Hausbrand, R.; Cherkashinin, G.; Ehrenberg, H.; Gröting, M.; Albe, K.; Hess, C.; Jaegermann, W. Fundamental Degradation Mechanisms of Layered Oxide Li-Ion Battery Cathode Materials: Methodology, Insights and Novel Approaches. Mater. Sci. Eng. B 2015, 192, 3-25.

(8) Buchberger, I.; Seidlmayer, S.; Pokharel, A.; Piana, M.; Hattendorff, J.; Kudejova, P.; Gilles, R.; Gasteiger, H. A. Aging Analysis of Graphite/LiNi ${ }_{1 / 3} \mathrm{Mn}_{1 / 3} \mathrm{Co}_{1 / 3} \mathrm{O}_{2}$ Cells Using XRD, PGAA, and AC Impedance. J. Electrochem. Soc. 2015, 162, A2737-A2746.

(9) de Biasi, L.; Kondrakov, A. O.; Geßwein, H.; Brezesinski, T.; Hartmann, P.; Janek, J. Between Scylla and Charybdis: Balancing Among Structural Stability and Energy Density of Layered NCM Cathode Materials for Advanced Lithium-Ion Batteries. $J$. Phys. Chem. C 2017, 121, 26163-26171.

(10) Ishidzu, K.; Oka, Y.; Nakamura, T. Lattice Volume Change during Charge/Discharge Reaction and Cycle Performance of $\mathrm{Li}\left[\mathrm{Ni}_{x} \mathrm{Co}_{y} \mathrm{Mn}_{z}\right] \mathrm{O}_{2}$. Solid State Ionics 2016, 288, 176179.

(11) Jung, S. K.; Gwon, H.; Hong, J.; Park, K. Y.; Seo, D. H.; Kim, H.; Hyun, J.; Yang, W.; Kang, K. Understanding the Degradation Mechanisms of $\mathrm{LiNi}_{0.5} \mathrm{Co}_{0.2} \mathrm{Mn}_{0.3} \mathrm{O}_{2}$ Cathode Material in Lithium Ion Batteries. Adv. Energy Mater. 2014, 4, 1300787.

(12) Kim, H. R.; Woo, S. G.; Kim, J. H.; Cho, W.; Kim, Y. J. Capacity Fading Behavior of Ni-Rich Layered Cathode Materials in Li-Ion Full Cells. J. Electroanal. Chem. 2016, $782,168-173$.

(13) Kondrakov, A. O.; Schmidt, A.; Xu, J.; Geßwein, H.; Mönig, R.; Hartmann, P.; Sommer, H.; Brezesinski, T.; Janek, J. Anisotropic Lattice Strain and Mechanical Degradation of High- and Low-Nickel NCM Cathode Materials for Li-Ion Batteries. J. Phys. Chem. C 
2017, 121, 3286-3294.

(14) Sun, G.; Sui, T.; Song, B.; Zheng, H.; Lu, L.; Korsunsky, A. M. On the Fragmentation of Active Material Secondary Particles in Lithium Ion Battery Cathodes Induced by Charge Cycling. Extrem. Mech. Lett. 2016, 9, 449-458.

(15) Noh, H. J.; Youn, S.; Yoon, C. S.; Sun, Y. K. Comparison of the Structural and Electrochemical Properties of Layered $\mathrm{Li}\left[\mathrm{Ni}_{x} \mathrm{Co}_{y} \mathrm{Mn}_{z}\right] \mathrm{O}_{2}(x=1 / 3,0.5,0.6,0.7,0.8$ and 0.85) Cathode Material for Lithium-Ion Batteries. J. Power Sources 2013, 233, 121-130.

(16) Ryu, H. H.; Park, K. J.; Yoon, C. S.; Sun, Y. K. Capacity Fading of Ni-Rich $\mathrm{Li}\left[\mathrm{Ni}_{x} \mathrm{Co}_{y} \mathrm{Mn}_{1-x-y}\right] \mathrm{O}_{2}(0.6 \leq x \leq 0.95)$ Cathodes for High-Energy-Density Lithium-Ion Batteries: Bulk or Surface Degradation? Chem. Mater. 2018, 30, 1155-1163.

(17) Schweidler, S.; de Biasi, L.; Garcia, G.; Mazilkin, A.; Hartmann, P.; Brezesinski, T.; Janek, J. Investigation into Mechanical Degradation and Fatigue of High-Ni NCM Cathode Material: A Long-Term Cycling Study of Full Cells. ACS Appl. Energy Mater. 2019, 2, 7375-7384.

(18) Bianchini, M.; Roca-Ayats, M.; Hartmann, P.; Brezesinski, T.; Janek, J. There and Back Again-The Journey of $\mathrm{LiNiO}_{2}$ as a Cathode Active Material. Angew. Chemie Int. Ed. 2019, 58, 10434-10458.

(19) Li, H.; Zhang, N.; Li, J.; Dahn, J. R. Updating the Structure and Electrochemistry of $\mathrm{Li}_{x} \mathrm{NiO}_{2}$ for $0 \leq x \leq 1$. J. Electrochem. Soc. 2018, 165, A2985-A2993.

(20) Yoon, C. S.; Jun, D. W.; Myung, S. T.; Sun, Y. K. Structural Stability of $\mathrm{LiNiO}_{2}$ Cycled above 4.2 V. ACS Energy Lett. 2017, 2, 1150-1155.

(21) Li, W.; Reimers, J. N.; Dahn, J. R. In Situ X-Ray Diffraction and Electrochemical Studies of $\mathrm{Li}_{1-x} \mathrm{NiO}_{2}$. Solid State Ionics 1993, 67, 123-130.

(22) de Biasi, L.; Lieser, G.; Rana, J.; Indris, S.; Dräger, C.; Glatthaar, S.; Mönig, R.; Ehrenberg, H.; Schumacher, G.; Binder, J. R.; Geßwein, H. Unravelling the Mechanism of Lithium Insertion into and Extraction from Trirutile-Type $\mathrm{LiNiFeF}_{6}$ Cathode Material for Li-Ion Batteries. CrystEngComm 2015, 17, 6163-6174.

(23) Thompson, P.; Cox, D. E.; Hastings, J. B. Rietveld Refinement of Debye-Scherrer Synchrotron X-Ray Data from $\mathrm{Al}_{2} \mathrm{O}_{3}$. J. Appl. Crystallogr. 1987, 20, 79-83.

(24) Schweidler, S.; de Biasi, L.; Schiele, A.; Hartmann, P.; Brezesinski, T.; Janek, J. Volume Changes of Graphite Anodes Revisited: A Combined Operando X-ray Diffraction and 
In Situ Pressure Analysis Study. J. Phys. Chem. C 2018, 122, 8829-8835.

(25) Peres, J. P.; Weill, F.; Delmas, C. Lithium/Vacancy Ordering in the Monoclinic $\mathrm{Li}_{x} \mathrm{NiO}_{2}$ $(0.50 \leq x \leq 0.75)$ Solid Solution. Solid State Ionics 1999, 116, 19-27.

(26) Ghanty, C.; Markovsky, B.; Erickson, E. M.; Talianker, M.; Haik, O.; Tal-Yossef, Y.; Mor, A.; Aurbach, D.; Lampert, J.; Volkov, A.; Shin, J.-Y.; Garsuch, A.; Chesneau, F. F.; Erk. C. $\mathrm{Li}^{+}$-Ion Extraction/Insertion of Ni-Rich $\mathrm{Li}_{1+x}\left(\mathrm{Ni}_{y} \mathrm{Co}_{z} \mathrm{Mn}_{z}\right)_{W} \mathrm{O}_{2}(0.005<x<$ 0.03; $y: z=8: 1, w \approx 1)$ Electrodes: In Situ XRD and Raman Spectroscopy Study. ChemElectroChem 2015, 2, 1479-1486.

(27) Li, J.; Shunmugasundaram, R.; Doig, R.; Dahn, J. R. In Situ X-Ray Diffraction Study of Layered Li-Ni-Mn-Co Oxides: Effect of Particle Size and Structural Stability of CoreShell Materials. Chem. Mater. 2016, 28, 162-171.

(28) Kondrakov, A. O.; Geßwein, H.; Galdina, K.; de Biasi, L.; Meded, V.; Filatova, E. O.; Schumacher, G.; Wenzel, W.; Hartmann, P.; Brezesinski, T.; Janek, J. Charge-TransferInduced Lattice Collapse in Ni-Rich NCM Cathode Materials during Delithiation. $J$. Phys. Chem. C 2017, 121, 24381-24388.

(29) Dolotko, O.; Senyshyn, A.; Mühlbauer, M. J.; Nikolowski, K.; Ehrenberg, H. Understanding Structural Changes in NMC Li-Ion Cells by in Situ Neutron Diffraction. J. Power Sources 2014, 255, 197-203.

(30) Zhang, X.; Mauger, A.; Lu, Q.; Groult, H.; Perrigaud, L.; Gendron, F.; Julien, C. M. Synthesis and Characterization of $\mathrm{LiNi}_{1 / 3} \mathrm{Mn}_{1 / 3} \mathrm{Co}_{1 / 3} \mathrm{O}_{2}$ by Wet-Chemical Method. Electrochim. Acta 2010, 55, 6440-6449.

(31) Van der Ven, A.; Aydinol, M. K.; Ceder, G.; Kresse, G.; Hafner, J. First-Principles Investigation of Phase Stability in $\mathrm{Li}_{x} \mathrm{CoO}_{2}$. Phys. Rev. B 1998, 58, 2975-2987.

(32) de Biasi, L.; Schiele, A.; Roca-Ayats, M.; Garcia, G.; Brezesinski, T.; Hartmann, P.; Janek, J. Phase Transformation Behavior and Stability of $\mathrm{LiNiO}_{2}$ Cathode Material for Li-Ion Batteries Obtained from In Situ Gas Analysis and Operando X-Ray Diffraction. ChemSusChem 2019, 12, 2240-2250. 